\title{
Metabolic flux analysis for directing metabolism of Streptomyces olindensis from growth to anti-tumor drug (cosmomycin) production
}

\author{
Ana Katerine de Carvalho Lima Lobato*1,3, Raul Munoz-Hernandez ${ }^{1}$, \\ Renata L Araujo Furlan², Gabriel Padilla², Leandro M Garrido², \\ Gorete Ribeiro de Macedo $^{3}$ and Ferda Mavituna ${ }^{1}$
}

Address: ${ }^{1}$ The School of Chemical Engineering and Analytical Science, The University of Manchester, Manchester, UK, ${ }^{2}$ Institute of Biomedical Sciences, University of Sao Paulo, Sao Paulo, Brazil and ${ }^{3}$ Department of Chemical Engineering,, Federal University of Rio Grande do Norte, Natal, Brazil

Email: Ana Katerine de Carvalho Lima Lobato* - a.carvalho@manchester.ac.uk

* Corresponding author

from BioSysBio 2007: Systems Biology, Bioinformatics and Synthetic Biology

Manchester, UK. II-13 January 2007

Published: 8 May 2007

BMC Systems Biology 2007, I (Suppl I):P43 doi: I0.I I86/I752-0509-I-SI-P43

This abstract is available from: http://www.biomedcentral.com/I752-0509/I?issue=S I

(C) 2007 de Carvalho Lima Lobato et al; licensee BioMed Central Ltd.

\section{Introduction}

The aim of this work is to develop a computational model based on metabolic flux balancing methodology for the primary metabolism of Streptomyces olindensis and the biosynthesis of cosmomycin so that metabolic shifts in directing metabolism from growth to cosmomycin production can be investigated.

\section{Background}

Cosmomycin, an aromatic polyketide antibiotic complex produced by Streptomyces olindensis, belongs to anthracycline family of chemotherapy drugs. It is a powerful antitumor drug similar to doxorubicin and daunorubicin. The structure of cosmomycin consists of one tetracycline aglycon ( $\beta$-rhodomycinone) and six deoxysugars (two dTDPL-2-deoxifucose, two dTDP-L-rodosamine and two dTDPL-rodinose). The tetracycline aglycon, a polyketide structure, is obtained by condensation of one propionyl-CoA with nine acetate molecules derived from malonyl-CoA by the action of enzymes known as minimal Polyketide Synthetases (minimal PKS).

\section{Model construction}

The in silico metabolism was reconstructed involving more than 240 stoichiometrically balanced metabolic reactions in matrix formalism using the information from the literature and databases (top-down and bottom-up). Then, computational metabolic flux balancing method was used in order to obtain fluxes of all the metabolic reactions with linear programming and optimisation in GAMS environment (General Algebraic Modeling System). The objective function of optimisation was either the maximisation of the specific growth rate or the maximisation of the specific cosmomycin production rate. The experimental specific glucose uptake and growth rates were used as the model constraints, as appropriate. The solution of the metabolic model gave the specific growth and/or product formation rates as well as the specific rates of all 242 metabolic reactions.

\section{Results}

The comparison of internal metabolite fluxes between the maximisation of specific growth and cosmomycin production revealed important changes in fluxes related to energy production and redox balances (NADH, FADH2, 
and ATP), as well as oxygen consumption and CO2 generation when the metabolism shifts from growth to cosmomycin production. In addition, there was an important change in the fluxes of the TCA intermediates. This indicates that during growth maximisation more energy is required, so the TCA cycle is complete, more active and the aerobic respiration rate is increased. Another important observation is in the acetyl-CoA flux; during growth maximisation, this metabolite enters the TCA cycle but during cosmomycin maximisation all acetyl-CoA goes to malonyl-CoA, the precursor of this antibiotic. The TCA cycle is not complete in this case and depends on the anaplerotic reactions and 3-phosphoglycerate. The sensitivity analysis performed in GAMS also confirms this. This also highlights the reason for the inclusion of casamino acids in the culture medium in the experiments. Another important change is observed in the glucose-1P flux because during growth maximisation it goes to carbohydrate biosynthesis and during cosmomycin production it goes to this product.

\section{Conclusion}

The results of the model and the experiments for growth and cosmomycin production are in reasonable agreement which means that this model can be used to identify strategies for directing the metabolism from growth to secondary metabolism.

\section{Acknowledgements}

Coordenação de Aperfeiçoamento de Pessoal de Nível Superior, CAPES, Brazil

Conselho Nacional de Desenvolvimento Científico e Tecnológico, CNPq, Brazil.

\section{References}

I. Kim HB, Smith CP, Micklefield J, Mavituna F: Metabolic flux analysis for calcium dependent antibiotic (CDA) production in Streptomyces coelicolor. Metab Eng 2004, 6:31 3-325.

2. Furlan RLA, Watt SJ, Garrido LM, Amarante-Mendes GP, Nur-e-Alan M, Rohr J, Brana A, Mendez C, Salas JA, Sheil MM, Beck JL, Padilla G: DNA-Binding Properties of Cosmomycin D, an Anthracycline with Two Trisaccharide Chains. The journal of Antibiotics 2004, 57:647-654.

3. Pamboukian CRD: Produção do antitumoral retamicina por Streptomyces olindensis em processos descontínuos alimentados e contínuos. In Tese (Doutorado) - Escola Politécnica Universidade de São Paulo, São Paulo; 2003.

\section{Publish with Biomed Central and every scientist can read your work free of charge}

"BioMed Central will be the most significant development for disseminating the results of biomedical research in our lifetime. " Sir Paul Nurse, Cancer Research UK

Your research papers will be:

- available free of charge to the entire biomedical community

- peer reviewed and published immediately upon acceptance

- cited in PubMed and archived on PubMed Central

- yours - you keep the copyright

Submit your manuscript here:

http://www.biomedcentral.com/info/publishing_adv.asp 